\title{
Um jovem com hipocalcémia: um relato breve
}

Ana Rita Mendes,* Gonçalo Melo, ${ }^{* *}$ Ana Dantas***

\section{RESUMO}

Introdução: A coexistência de duas endocrinopatias é uma situação rara e cujo diagnóstico pode constituir um desafio. Descrição do caso: Doente de 32 anos iniciou queixas de dificuldade em manter ereção sustentada e lombalgia de ritmo mecânico, em 2011. As queixas foram interpretadas como estenose do canal raquidiano lombar com neuropatia mista.

Cerca de seis meses depois recorreu novamente a consulta aberta na sua unidade de saúde familiar, agora por parestesias generalizadas. Iniciou suplementação com magnésio e pediu-se avaliação analítica que mostrava hipocalcémia. Dez dias depois, por agravamento do quadro clínico, o utente decidiu recorrer ao serviço de urgência, tendo ficado internado no serviço de medicina interna para investigação da hipocalcémia. À data de alta apurou-se tiroidite auto-imune com hipotiroidismo subclínico e hipoparatiroidismo, tendo sido colocada a hipótese de síndroma poliglandular auto-imune.

Cerca de oito meses depois surgiu novo internamento no serviço de endocrinologia, motivado por quadro semelhante. Confirmaram-se os diagnósticos de hipotiroidismo e hipoparatiroidismo primários, mas a avaliação analítica realizada excluiu a etiologia auto-imune do hipoparatiroidismo, tendo ficado assim descartada a hipótese diagnóstica de síndroma poliglandular auto-imune. $O$ resultado do teste genético, entretanto realizado para despiste de etiologia genética, veio mais tarde confirmar a existência de polimorfismo do gene CASR.

Comentário: $O$ caso clínico que descrevemos mostra que nem sempre é possível enquadrar os sinais e sintomas numa única entidade nosológica. A marcha diagnóstica revelou-se complexa, mas foi essencial para esclarecer o diagnóstico. Neste sentido, o teste genético confirmou o polimorfismo do gene CASR. O polimorfismo resulta num ganho de função do recetor que leva à inibição da secreção da PTH e reabsorção de cálcio, com aumento da excreção urinária.

Palavras-chave: Hipoparatiroidismo; Poliendocrinopatias Auto-imunes; Hipotiroidismo.

\section{INTRODUÇÃO}

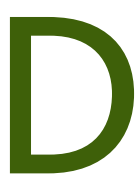

escreve-se um caso clínico raro em que coexistem duas patologias endócrinas. Além da raridade do caso, é interessante notar que, ao contrário do que habitualmente acontece, não existia apenas uma entidade clínica responsável pelo quadro clínico mas duas entidades nosológicas: hipoparatiroidismo primário e hipotiroidismo primário. Além disso, a marcha diagnóstica complexa foi essencial para o desfecho do caso, bem como o papel do médico de família como gestor do doente, promovendo a adaptação à doença.

\footnotetext{
*Médica Interna de Medicina Geral e Familiar. Unidade de Saúde Familiar Tílias, ACES Lisboa Norte, Lisboa. anarita_m@msn.com

**Médico Assistente de Medicina Geral e Familiar. Unidade de Saúde Familiar Tílias, ACES Lisboa Norte, Lisboa.

***Médica Assistente de Medicina Geral e Familiar. Unidade de Saúde Familiar São Martinho de Alcabideche, ACES Cascais, Lisboa.
}

Pretendemos com este artigo melhorar o conhecimento acerca destas entidades nosológicas, elucidando o seu processo de diagnóstico, mostrando que mesmo em casos raros a medicina geral e familiar tem um papel essencial.

\section{DESCRIÇÃO DO CASO CLÍNICO}

Doente de 32 anos, sexo masculino, com antecedentes pessoais de psoríase vulgar sob calcipotriol e corticoides tópicos, sem outras doenças crónicas ou hábitos toxifílicos. Sem história familiar de endocrinopatias ou nefropatias.

Em 2011 recorreu ao médico assistente por queixas de dificuldade em manter ereção sustentada e lombalgia à direita de ritmo mecânico. As queixas foram interpretadas no contexto de estenose do canal raquidiano lombar com neuropatia mista. Foram pedidas avaliação analítica sumária, que não mostrava alterações reve- 
lantes, e TAC da coluna lombar que revelava hérnia L4/L5, sem compromisso radicular, discartrose L3/L4 e osteólise L5. O utente foi encaminhado para a consulta de urologia para esclarecimento da disfunção sexual.

Seis meses depois, o doente recorreu à consulta aberta da sua Unidade de Saúde Familiar com queixas de parestesias generalizadas, mais frequentes nos grandes peitorais e braços, de predomínio diurno e com cerca de duas semanas de evolução. Iniciou-se suplementação oral com magnésio e realizou nova avaliação analítica com ionograma que mostrava hipocalcémia (Ca2+ total $6,9 \mathrm{mg} / \mathrm{dL}$; Ca2+ ionizado $0,78 \mathrm{mg} / \mathrm{dL}$ ) com albumina normal e deu-se indicação para agendar consulta com o seu médico de família. Contudo, dez dias depois, por agravamento do quadro, o doente recorreu ao serviço de urgência do hospital de referência. À entrada no serviço de urgência apresentava quadro de dejeções líquidas, sem sangue, muco ou pus e vómitos aquosos, acompanhados de agravamento das parestesias e espasmos, agora sobretudo de localização perioral, dos membros inferiores e superiores. À observação apresentava hiporreflexia generalizada com sinal de Chvostek e Trosseau despertáveis bilateralmente.

Realizou, no SU, avaliação analítica que confirmava a hipocalcémia com discreta diminuição da PTH, decidindo-se o internamento no serviço de medicina interna para investigação da hipocalcémia em doente jovem.

Durante o internamento foram realizadas ecografia da tiroide e paratiroide, abdominal e renal, que não mostravam alterações e TAC cervico-toraco-abdomino-pélvica que revelava apenas um divertículo do esófago com $13 \mathrm{~mm}$. Da avaliação analítica efetuada, e que se apresenta na tabela 1 , constata-se diminuição da PTHi, hipocalcémia com hipercalciúria em doente com albuminemia normal, fosfatúria e magnesiúria, TSH aumentada com FT4 normal e anticorpos antitiroideus positivos.

O doente teve alta com os diagnósticos de tiroidite auto-imune com hipotiroidismo subclínico e hipoparatiroidismo, colocando-se a hipótese de se enquadrar numa síndroma poliglandular auto-imune. Foi medicado com clorotalidona pelo seu efeito hipocalciúrico. Iniciou suplementação com magnésio oral, carbonato de cálcio e cacitriol e, para correção da função tiroideia, iniciou levotiroxina. Manteve seguimento em consulta de medicina interna, nefrologia e seguimento trimestral em consulta de medicina geral e familiar para

\begin{tabular}{|c|c|}
\hline Hemoglobina & $13.8 \mathrm{~g} / \mathrm{dL}$ \\
\hline VGM & $92.3 \mathrm{fL}$ \\
\hline CHGM & $31.0 \mathrm{~g} / \mathrm{dL}$ \\
\hline Leucócitos & $5,1 \times 10^{9} / L$ \\
\hline Neutrófilos & $60,2 \%$ \\
\hline Linfócitos & $25,6 \%$ \\
\hline Monócitos & $12,8 \%$ \\
\hline Eosinófilos & $1,1 \%$ \\
\hline Basófilos & $0,3 \%$ \\
\hline Plaquetas & $171 \times 10^{9} / \mathrm{L}$ \\
\hline Glicose & $122 \mathrm{mg} / \mathrm{dL}$ \\
\hline Ureia & $51 \mathrm{mg} / \mathrm{dL}$ \\
\hline Creatinina & $1,00 \mathrm{mg} / \mathrm{dL}$ \\
\hline Sódio & $146 \mathrm{mEq} / \mathrm{L}$ \\
\hline Potássio & $3,6 \mathrm{mEq} / \mathrm{L}$ \\
\hline Cloreto & $104 \mathrm{mEq} / \mathrm{L}$ \\
\hline Cálcio total & $6,5 \mathrm{mg} / \mathrm{dL}$ \\
\hline Fósforo inorgânico & $2,4 \mathrm{mg} / \mathrm{dL}$ \\
\hline Magnésio & $1,5 \mathrm{mg} / \mathrm{dL}$ \\
\hline Proteína C Reativa & $<0,50 \mathrm{mg} / \mathrm{dL}$ \\
\hline CK & $304 \mathrm{U} / \mathrm{L}$ \\
\hline CKMB & $15 \mathrm{U} / \mathrm{L}$ \\
\hline Albumina & $4,70 \mathrm{~g} / \mathrm{dL}$ \\
\hline LDH & 794U/L \\
\hline Cálcio urinário & $24 \mathrm{mg} / \mathrm{dL}$ \\
\hline Fósforo urinário & $<5,5 \mathrm{mg} / \mathrm{dL}$ \\
\hline PTHi & $9 \mathrm{pg} / \mathrm{mL}$ \\
\hline 25-OH-vitD & $27,5 \mathrm{ng} / \mathrm{mL}$ \\
\hline TSH & 4,98uUI/mL \\
\hline FT4 & $0,83 \mathrm{ng} / \mathrm{dL}$ \\
\hline Anticorpos anti-tiroglobulina & Positivos \\
\hline Anticorpos anti-peroxidades & Positivos \\
\hline Anticorpos anti suprarrenal & Negativos \\
\hline Anticorpos anti-paratiroide & Negativos \\
\hline
\end{tabular}

realização periódica de ionograma, por forma a ajustar a terapêutica mais frequentemente para prevenir a ocorrência de novas crises. $\mathrm{O}$ aumento da periodicidade 
das consultas com o seu médico assistente permitiram também tranquilizar um pouco o doente que se mostrava ansioso em relação ao prognóstico da doença e necessitava de apoio para aprender a viver com uma doença crónica.

Entretanto, o doente foi visto na consulta de urologia que o referenciou para a consulta externa de cirurgia vascular. Após realização de prova de esforço e eco-doppler carotídeo e peniano, vertebral e abdominal excluiu-se disfunção eréctil secundária, a doença arterial peniana, atribuindo-se a disfunção eréctil a causas microangiopáticas.

Cerca de oito meses depois surgiu novo internamento, num outro hospital por alteração da área de referenciação hospitalar, no serviço de endocrinologia. O doente apresentava quadro clínico semelhante ao anteriormente descrito, mas sem alterações ao exame objetivo.

Pretendia-se com este internamento confirmar os diagnósticos de hipoparatiroidismo e hipotiroidismo e despistar outra endocrinopatia ou doença auto-imune que permitisse enquadrar o doente numa síndroma poliglandular auto-imune.

A avaliação analítica realizada mostrava hipocaliémia, hipocalcémia com normofosfatémia, hipomagnesémia e alcalose metabólica. Foram pedidos doseamentos dos anticorpos anti-insulina, anti-21-hidroxilase e anti-paratiroideia, que vieram negativos. Foram também pedidos doseamentos das hormonas GH (SmC, IGFBP3), LH/FSH, Testosterona, ACTH/cortisol, Prolactina que, face à sua normalidade, excluíram outra doença endócrina. Foi ainda realizada a prova do tetracosactido, que foi negativa para insuficiência da suprarrenal ou diminuição da reserva cortico-suprarenal.

Assim, o doente teve alta com os diagnósticos de hipoparatiroidismo primário e hipotiroidismo primário, excluindo quase certamente tratar-se de uma síndroma poliglandular. Para esclarecimento etiológico do hipoparatiroidismo foi então pedido estudo genético que ficou em curso.

À data de alta houve ajuste terapêutico, parou a clorotalidona e iniciou hidroclorotiazida e amiloride, devido a hipocaliémias iatrogénicas persistentes, mantendo a restante medicação (levotiroxina, carbonato de cálcio, vitamina $\mathrm{D}$ ativada e magnésio oral).

Após a alta, o doente agendou consulta com o seu médico de família para pedir uma segunda opinião acerca da alteração terapêutica instituída pelo serviço de endocrinologia, uma vez que a medicina interna pretendia manter terapêutica com clorotalidona. Aqui, o médico de família incentiva o doente a manter seguimento num único centro hospitalar e, após revisão do caso, incentiva alteração da terapêutica como proposta pela endocrinologia, pois a hidroclotiazida associada ao amiloride diminui a excreção urinária de cálcio, à semelhança da clorotalidona mas, ao contrário desta última, é poupador de potássio.

Cerca de três meses depois, o resultado do estudo genético confirmou que o doente apresentava um polimorfismo no gene CASR (variante Arg990Gly), excluindo definitivamente a possibilidade de síndroma poliglandular auto-imune.

Após confirmação da alteração genética, os familiares de primeiro grau foram convocados para uma consulta com o médico assistente a fim de explicar a necessidade de alargar o estudo genético. A família mantinha-se tranquila em relação à possibilidade de haver outros elementos com esta alteração e pretendia a realização do teste. Foi então efetuado o estudo genético nos familiares de $1 .^{\circ}$ grau do doente, cujo resultado foi negativo, tratando-se provavelmente de uma mutação de novo.

Presentemente, o doente mantém-se estável com a terapêutica acima descrita, tendo havido inclusivamente regressão do quadro de disfunção erétil.

Mantém seguimento em consulta de endocrinologia e em consulta de medicina geral e familiar.

\section{COMENTÁRIO}

O caso clínico que descrevemos mostra que por vezes nem sempre conseguimos enquadrar os sinais e sintomas numa única entidade nosológica. Desde o início ficou claro estarmos perante uma tiroidite auto-imune. Este diagnóstico baseou-se fundamentalmente na avaliação laboratorial com auto-anticorpos positivos uma vez que a ecografia da tiróide se mostrou normal. Na verdade sabemos que as tiroidites de Hashimoto cursam com anticorpos anti-peroxidase e anti-tiroglobulina positivos em $90-85 \%$ dos doentes, não sendo as alterações ecoestruturais da tiroide condição necessária ao diagnóstico. ${ }^{1}$

Apesar de serem claros os diagnósticos de hipoparatiroidismo primário e hipotiroidismo primário, ao 
não existir evidência de outra endocrinopatia ou doença do foro auto-imune não foi possível enquadrar este caso clínico numa síndroma poliglandular auto-imune. Na verdade, ele nunca poderia corresponder à síndroma poligladular tipo 1 em que a candidíase mucocutânea está sempre presente, nem à síndroma poliglandular tipo 2 em que a associação é de doença da tiroideia com diabetes mellitus e em que o hipoparatiroidismo é extremamente raro. Embora pouco provável, ainda foi considerada a hipótese de tratar-se de uma síndroma poliglandular tipo $3,^{2-4}$ mas o teste genético entretanto realizado confirmou a hipótese da diminuição do PTHi resultar de um polimorfismo no gene CASR, receptor de cálcio existente na superfície da paratiroide. O alelo 990G situa-se na extremidade carboxil-terminal do domínio intracelular, podendo condicionar alteração da conformação do receptor. ${ }^{5}$ Isto resulta num ganho de função do receptor ${ }^{6}$ que condiciona inibição da secreção de PTH e da reabsorção de cálcio, com aumento da excreção urinária. ${ }^{7}$

O polimorfismo 990G está associado na literatura a casos de hiperparatiroidismo. ${ }^{5,7}$ Contudo, o caso apresentado cursou com valores diminuídos de PTHi, que normalizaram após o primeiro internamento. Assim sendo, consideramos que esta alteração pode ser multifactorial. Por um lado, o polimorfismo parece estar relacionado com níveis mais baixos de PTH, inclusive em doentes com hiperparatiroidismo; 5 por outro lado, sabe-se que a depleção de magnésio pode ser suficiente para levar a hipoparatiroidismo funcional por défice da secreção de PTH ou aumento da resistência periférica à hormona. ${ }^{8}$ Sabe-se, porém, que a hipomagnesémia também poderá ser consequência e não causa do hipoparatiroidismo. ${ }^{9}$

Neste caso, a realização do teste genético foi essencial, não só porque possibilitou esclarecer o diagnóstico, mas também porque a deteção da mutação pode ter implicações importantes na vida do doente. Ao que parece, este polimorfismo parece estar implicado no aparecimento de nefrolitíase e nefrocalcinose ${ }^{5-7}$ pelo que convém que mantenha um seguimento médico periódico.

Em relação à terapêutica, ela visa essencialmente o controlo sintomático. Deste modo, é objetivo terapêutico aumentar os níveis séricos de cálcio e vitamina $\mathrm{D}$ e controlar a função tiroideia. Assim, o doente realiza suplementação oral com cálcio e vitamina D e diuréticos tiazídicos que permitem reduzir a excreção urinária de cálcio. Além do reforço hídrico recomendado ao doente, estes diuréticos são o elemento chave que permitirá diminuir o risco de nefrolitíase e nefrocalcinose ao reduzirem a excreção urinária de cálcio, aumentada no doente.

Outro aspeto interessante neste caso clínico relaciona-se com o diagnóstico de disfunção erétil microangiopática. Como se depreende da marcha diagnóstica, este foi um diagnóstico de exclusão colocado na altura pelos colegas. O facto é que após terapêutica de correção das doenças de base houve uma regressão da sintomatologia, apesar de o doente se encontrar a realizar terapêutica com diuréticos que, como vimos, são essenciais ao controlo da doença e para a sua qualidade de vida. Assim sendo, e tendo por base o descrito na literatura, a disfunção erétil estará provavelmente relacionada com o hipotiroidismo. Sabe-se que as alterações da função tiroideia, sejam elas hiper ou hipotiroidismo, afetam a função eréctil, pelo que nestes casos o doseamento hormonal é recomendado. ${ }^{10-11}$

Em suma, trata-se de um caso clínico complexo e rico, não só pela marcha diagnóstica, mas pela sua abrangência e no qual o médico de família teve um papel importante, apesar de muitos dos diagnósticos terem sido realizados ao nível de cuidados secundários. Para além do seguimento clínico do doente em consulta de vigilância trimestral, com realização de ionograma, do controlo da sintomatologia e da prevenção de crises através do ajuste terapêutico, o médico de família pode auxiliar o doente a compreender a doença e a saber lidar com a sintomatologia de forma a promover a adaptação do doente à doença, através de medidas educativas como o reforço da ingesta hídrica ou o reforço do magnésio oral em períodos de maior esforço físico. Isto permite diminuir a ansiedade do doente, porque ele sente que tem um papel ativo no controlo e na prevenção da sintomatologia e co-morbilidades. Foi igualmente importante nesse processo o agendamento de consultas marcadas periodicamente que permitiram que o doente se sentisse mais apoiado ao longo de toda a marcha diagnóstica, sendo a escuta ativa uma ferramenta essencial ao dispor do médico de família, contribuindo igualmente para avaliação e eventual intervenção, quando necessário, no reajuste da dinâmica 
familiar, alterada pela ocorrência de uma doença crónica no seio de um dos seus elementos.

\section{REFERÊNCIAS BIBLIOGRÁFICAS}

1. Lee SL, Odeke S, Nagelberg SB. Hashimoto tyroiditis. Medscape.com [homepage]; updated 2014 Jun 3 [cited 2013 Dec 22]. Available from: http://emedicine.medscape.com/article/120937-overview

2. Aldasouqi SA, Akinsoto OP, Jabbour SA. Type I polyglandular autoimmune syndrome. Medscape.com [homepage]; updated 2014 Aug 28 [cited 2013 Dec 22]. Available from: http://emedicine.medscape.com/article/124183-overview

3. Sivarajah S, Fan CY,Akinsoto OP. Type Il polyglandular autoimmune syndrome. Medscape.com [homepage]; updated 2014 Aug 28 [cited 2013 Dec 22]. Available from: http://emedicine.medscape.com/article/124287-overview

4. Aung K, Talavera F, Chausmer AB. Type III polyglandular autoimmune syndrome. Medscape.com [homepage]; 2014 Aug 28 [cited 2013 Dec 22]. Available from: http://emedicine.medscape.com/article/124398overview

5. Corbetta S, Eller-Vainicher C, Filopanti M, Saeli P, Vezzoli G, Arcidiacono T, et al. R990G polymorphism of the calcium-sensing receptor and renal calcium excretion in patients with primary hyperparathyroidism. Eur J Endocrinol. 2006;155(5):687-92.

6. Vezzoli G, Terranegra A, Arcidiacono T, Biasion R, Coviello D, Syren ML, et al. R990G polymorphism of calcium-sensing receptor does produce a gain-of-function and predispose to primary hypercalciuria. Kidney Int. 2007;71(11):1155-62.

7. Vezzoli G, Scillitani A, Corbetta S, Terranegra A, Dogliotti E, Guarnieri V, et al. Polymorphisms at the regulatory regions of the CASR gene in- fluence stone risk in primary hyperparathyroidism. Eur J Endocrinol. 2011;164(3):421-7.

8. Anselmo J, Martins J, Matos L, Boavida J, Carreiras F, Correia G, et al. Hipoparatiroidismo crónico: revisão de 5 casos clínicos [Chronic hypoparathyroidism: review of 5 case reports]. Acta Med Por. 1991; 4(2):83-6. Portuguese

9. Kifor O, McElduff A, LeBoff MS, Moore Jr FD, Butters R, Gao P, et al. Activating antibodies to the calcium-sensing receptor in two patients with autoimmune hypoparathyroidism. J Clin Endocrinol Metab. 2004; 89(2):548-56.

10. Krassas GE, Tziomalos K, Papadopoulou F, Pontikides N, Perros P. Erectile dysfunction in patients with hyper- and hypothyroidism: how common and should we treat? J Clin Endocrinol Metab. 2008;93(5):1815-9.

11. Nikoobakht MR, Aloosh M, Nikoobakht N, Mehrsay AR, Biniaz F, Karjalian MA. The role of hypothyroidism in male infertility and erectile dysfunction. Urol J. 2012;9(1):405-9.

\section{CONFLITO DE INTERESSES}

Os autores declaram não ter conflitos de interesses.

\author{
ENDEREÇO PARA CORRESPONDÊNCIA \\ Ana Rita Mendes \\ Rua Padre Carlos dos Santos, Bloco B - $1^{\circ}$ \\ 1500-901 LISBOA \\ anarita_m@msn.com
}

Recebido em 15-10-2014

Aceite para publicação em 08-06-2015

Artigo escrito ao abrigo do novo acordo ortográfico.

\section{ABSTRACT}

\section{A YOUNG MAN WITH HYPOCALCAEMIA: A BRIEF REPORT}

Introduction: The coexistence of two endocrine diseases is rare. Making the right diagnoses can be challenging.

Case report: A 32 year-old man complained of difficulty in maintaining a sustained erection and mechanical low back pain in 2011. Those complaints were attributed to lumbar spinal stenosis with mixed neuropathy. Six months later he went to his family doctor with generalized paraesthesia. Supplementation with oral magnesium was started and hypocalcaemia was found. Ten days later due to exacerbation of his condition, he went to the emergency department of a local hospital and was admitted to an internal medicine ward for investigation of hypocalcaemia. He was discharged with the diagnosis of autoimmune thyroiditis with subclinical hypothyroidism and hypoparathyroidism. This raised the possibility of polyglandular autoimmune syndrome. Eight months later, he was admitted to the endocrinology ward with similar symptoms. The diagnoses of hypoparathyroidism and primary hypothyroidism were made but an autoimmune aetiology for hypoparathyroidism was ruled out. The results of genetic testing confirmed the existence of a polymorphism in the CASR gene.

Comment: This case report shows that we cannot always fit signs and symptoms into the diagnosis of a single disease. Many diagnostic tests were necessary to make the right diagnosis in this case. Genetic testing confirmed the polymorphism of the CASR gene. This polymorphism results in amplification of function of the receptor that leads to the inhibition of PTH secretion and resorption of calcium with increased urinary excretion.

Keywords: Hypoparathyroidism; Polyendocrinopathies, Autoimmune; Hypothyroidism. 